\title{
"Who wants to be a penguin?"-Conceptualisation of leadership and its impact on leader development practices among medical doctors in Uganda
}

\author{
Julius Lukwago ${ }^{1}$, Ana Martins ${ }^{2}$ \\ University of KwaZulu-Natal
}

\begin{abstract}
Leader development practices associated with expert leadership effectiveness is underresearched, particularly within the natural sciences such as medicine and engineering. Yet, increasingly these scientists are taking on leadership roles in their organisations, considering that they are the most technically qualified. Mintz and Stoller (2014) observe that the nature of health organisations and how physicians develop primarily emphasises the physician as a lone leader, compounding the individual characteristics common to such scientists-selfdirected, confident and independent-making collaboration with others an even greater challenge. Some studies suggest that scientists, in general, struggle with social skills. Given the social phenomena that is leadership, how such leaders develop, and the influence of context was the subject of this study. Using social identity theory and the theory of planned behaviour, we apply a constructionist lens to the question, "how do contextual influences affect leader development among natural scientists?" The research presented here emanates from the qualitative phase of a broader mixed-methods comparative study that examined perceptions and experiences of natural scientists on leader development in comparison with their non-scientist colleagues. Through thematic analysis of semi-structured interviews conducted among ten senior medical professionals currently holding leadership positions in health organisations, this article presents findings on the contextual factors that affect leader development. It then suggests approaches that leaders and policy elites in the medical field can advance to create an environment that engenders the learning of leadership. We found that leader-identity, self-efficacy, structural limitations and subjective norms, meaningfully attenuate the appetite for leader development activities.
\end{abstract}

Keywords: contextual leadership, leader development; leader identity; natural scientists; physicians. 